\title{
Systematic review and meta-analysis of diagnostic methods for occlusal surface caries
}

\author{
Svetlana Kapor ${ }^{1} \cdot$ Mila Janjic Rankovic $^{2} \cdot$ Yegane Khazaei $^{1,3} \cdot$ Alexander Crispin $^{3} \cdot$ Ina Schüler $^{4}$. \\ Felix Krause $^{5} \cdot$ Adrian Lussi $^{6,7} \cdot$ Klaus Neuhaus $^{8,9} \cdot$ Florin Eggmann $^{8} \cdot$ Stavroula Michou $^{10} \cdot$ Kim Ekstrand $^{10}$. \\ Marie-Charlotte Huysmans ${ }^{11}$. Jan Kühnisch ${ }^{1,12}$ (])
}

Received: 7 September 2020 / Accepted: 1 June 2021 / Published online: 14 June 2021

(c) The Author(s) 2021

\begin{abstract}
Aim This systematic review and meta-analysis aimed to assess the diagnostic performance of commonly used methods for occlusal caries diagnostics, such as visual examination (VE), bitewing radiography (BW) and laser fluorescence (LF), in relation to their ability to detect (dentin) caries under clinical and laboratory conditions.

Materials and methods A systematic search of the literature was performed to identify studies meeting the inclusion criteria using the PIRDS concept $(N=1090)$. A risk of bias $(\mathrm{RoB})$ assessment tool was used for quality evaluation. Reports with low/moderate RoB, well-matching thresholds for index and reference tests and appropriate reporting were included in the meta-analysis ( $N=37 ; 29$ in vivo/8 in vitro). The pooled sensitivity (SE), specificity (SP), diagnostic odds ratio (DOR) and areas under ROC curves (AUCs) were computed.

Results SP ranged from 0.50 (fibre-optic transillumination/caries detection level) to 0.97 (conventional BW/dentine detection level) in vitro. AUCs were typically higher for BW or LF than for VE. The highest AUC of 0.89 was observed for VE at the $1 / 3$ dentin caries detection level; SE (0.70) was registered to be higher than SP (0.47) for VE at the caries detection level in vivo.

Conclusion The number of included studies was found to be low. This underlines the need for high-quality caries diagnostic studies that further provide data in relation to multiple caries thresholds.

Clinical relevance VE, BW and LF provide acceptable measures for their diagnostic performance on occlusal surfaces, but the results should be interpreted with caution due to the limited data in many categories.
\end{abstract}

Keywords Occlusal caries $\cdot$ Pit and fissure caries $\cdot$ Caries detection $\cdot$ Caries diagnostics $\cdot$ Visual examination $\cdot$ Bitewing radiography $\cdot$ Laser fluorescence measurements $\cdot$ Fibre-optic transillumination $\cdot$ Systematic review $\cdot$ Meta-analysis .

Diagnostic performance $\cdot$ Accuracy $\cdot$ Sensitivity $\cdot$ Specificity

\section{Introduction}

Over the last several decades, occlusal surfaces have been found to be one of the most prevalent sites for caries development in children and adolescents, mainly due to their anatomical susceptibility [1-6]. Because a valid and reproducible caries diagnosis and assessment could not be made by visual examination (VE) alone, there was a consistent demand for additional diagnostic devices for caries detection and diagnostics in pits and fissures. In addition to VE,

Jan Kühnisch

jkuehn@dent.med.uni-muenchen.de

Extended author information available on the last page of the article conventional bitewing radiography (conventional BWR), digital bitewing radiography (digital BWR) and laser fluorescence (LF) measurements [7] were used in clinical practice or specifically introduced on the dental market in order to overcome the limitations of visual and/or tactile examination as well as to image and/or quantify the caries process to a certain degree [8]. On the basis of the acquired diagnostic information, the clinician should be enabled to make individual decisions about caries monitoring, prevention and/or operative intervention [9-11].

Numerous in vitro and in vivo caries detection, diagnostic, assessment and/or monitoring studies have been designed, conducted and published during the last few decades to describe the diagnostic performance of test methods 
in terms of validity (the diagnostic accuracy in relation to a reference standard) and intra-/inter-examiner reliability (the reproducibility of a diagnosis between different time points and examiners). Most recently, systematic reviews and metaanalyses have merged the available data and drawn conclusions mainly separately for each diagnostic method [12-16]. In addition, this author group [13-15] has mentioned substantial heterogeneity between the included diagnostic studies, and problematically, little attention has been paid to this important methodological issue so far; therefore, potential methodological sources of bias might be undetected and, furthermore, may also potentially skew meta-analysis data. Regarding this aspect, each diagnostic trial should ideally be designed similarly and should use equal scientific standards and protocols to generate comparable results that decrease the risk of bias (RoB) as much as possible. In contrast, previously published systematic reviews describe and report heterogeneity but do not exclude studies with a potentially high RoB. Therefore, this systematic review of the literature and meta-analysis was aimed, first, to identify caries diagnostic studies on pits and fissures that are tested with commonly used diagnostic methods, second, to evaluate study quality and identify only those studies with low/moderate RoB and, finally, to provide meta-analytic data on the diagnostic performance of clinically relevant detection and diagnostic methods.

\section{Material and methods}

The methodology of this systematic review was influenced by several recommendations or guidelines. The QUADAS 2 tool $[17,18]$, which was designed for the quality assessment of diagnostic accuracy studies, provided the basis for the RoB assessment. Here, the most recently published draft of the 'Cochrane Handbook for Diagnostic Test Accuracy Reviews' was also used [19]. The writing of this systematic review strictly followed the PRISMA-DTA statement (Preferred Reporting Items for Systematic Reviews and Meta-Analyses of Diagnostic Test Accuracy Studies) for diagnostic studies in its latest version [20]. The PRISMADTA group developed criteria to evaluate the validity and applicability of diagnostic studies and to enhance the replicability of systematic reviews in this area. The present systematic review was registered on the PROSPERO platform (CRD42017069894).

\section{Search strategy}

The research question, inclusion and exclusion criteria and search strategy were conducted on the basis of the PIRD concept [21]. Basically, this systematic review of the literature included in vitro and in vivo diagnostic studies that tested the diagnostic accuracy and/or reliability of different diagnostic methods for primary caries detection and assessment in human permanent posterior teeth (premolars and molars). In vivo studies were included regardless of the age of the population and the number of included patients or teeth. Studies containing information on primary teeth or teeth with restorations, secondary caries or artificially induced caries lesions were excluded. With respect to its clinical relevance, the following index tests were included in the search: VE, conventional BWR, digital BWR, LF measurements (DIAGNOdent 2095 or 2190, KaVo, Biberach, Germany), fibre-optic transillumination (FOTI, IC Lercher, Stockach, Germany) and quantitative light-induced fluorescence (QLF, Inspektor Research Systems, Amsterdam, The Netherlands). Other index test methods were not considered in this review. An essential characteristic of studies on diagnostic accuracy was the inclusion of a reference test, frequently also named the 'gold standard' or 'reference standard'. The included in vitro studies had to use any histological technique to validate the 'true' caries extension; otherwise, the studies were excluded. Under in vitro conditions, several histological techniques, e.g. slices, grinding, hemisection or microradiography, are well-established which fulfil the before-mentioned prerequisite. In clinical studies, cavity preparation or biopsy can be considered equivalent to provide proof about the presence of any (dentin) caries [22]. As dental radiography was commonly applied under clinical conditions as well, it was, therefore, also included [23, 24]. In relation to the previously formulated aims and the corresponding inclusion and exclusion criteria, a structured search of the literature was initiated in accordance with the mnemonic PIRD recommendations [21]. This concept included information about the study material or population, the selected index tests, possible reference tests and diagnoses of interest (outcomes). The final consented search items are shown in Table 1.

\section{Basic literature search and study selection according to PRISMA recommendations}

The systematic search of the literature was performed in the MEDLINE (via PubMed) and EMBASE (via Ovid) electronic literature databases using the consented search terms (Table 1) according to standard procedures [20, 25]. The search included all publications that were listed until 31 December 2018 in the databases and were written in English. Grey literature was not included. Additionally, reference lists of included studies and reviews were screened to identify any studies that may have been missed. A few studies $(N=4)$ were found in result of manual searches. 
Table 1 Documentation of keywords according to the PIRDS concept (Campbell et al. 2015)

\begin{tabular}{|c|c|c|c|c|c|c|}
\hline Population/problem (P) & & Index test (I) & & Reference test (R) & & Diagnose and study type (D/S) \\
\hline $\begin{array}{l}\text { Caries } \\
\text { Decay } \\
\text { AND } \\
\text { Occlusal } \\
\text { Fissure }\end{array}$ & AND & $\begin{array}{l}\text { Visual } \\
\text { Clinical } \\
\text { Clinically } \\
\text { Inspect* } \\
\text { ICDAS } \\
\text { Bitewing } \\
\text { Conventional Radiography } \\
\text { Digital Radiography } \\
\text { Radiogra* } \\
\text { Film } \\
\text { Analo* } \\
\text { X ray } \\
\text { Xray } \\
\text { Speed } \\
\text { Roentge* } \\
\text { Radiology } \\
\text { Radiol* } \\
\text { Laser fluorescence } \\
\text { Diagnodent } \\
\text { FOTI } \\
\text { DiFOTI } \\
\text { Di(FOTI) } \\
\text { Fiber } \\
\text { Fibre } \\
\text { Transillumination } \\
\text { Optic } \\
\text { Opti* } \\
\text { QLF } \\
\text { Quantit* } \\
\text { Laser } \\
\text { Light } \\
\text { Induced }\end{array}$ & AND & $\begin{array}{l}\text { Validity } \\
\text { Validation } \\
\text { Valid* } \\
\text { Accuracy } \\
\text { Sensitivity } \\
\text { Specificity } \\
\text { SE } \\
\text { SP } \\
\text { ROC } \\
\text { Az } \\
\text { Reproducibility } \\
\text { Reproducib* } \\
\text { Reliab* } \\
\text { Reliability } \\
\text { Kappa } \\
\text { Threshold } \\
\text { Cut off } \\
\text { Performance } \\
\text { Histolog* } \\
\text { Micro } \\
\text { Micro computed } \\
\text { CT } \\
\text { *CT }\end{array}$ & AND & $\begin{array}{l}\text { Systemati* Review } \\
\text { Meta-Analysis } \\
\text { Diagnos* } \\
\text { Diagnost* } \\
\text { Detection } \\
\text { Detect } \\
\text { Detect* } \\
\text { Assessm* } \\
\text { Vivo } \\
\text { Vitro } \\
\text { Study } \\
\text { Studies }\end{array}$ \\
\hline
\end{tabular}

MeSH terms which were used to search the PubMed and EMBASE databases: ((Caries or Decay) AND (Occlusal or Fissure) AND (Visual or Clinical or Clinically or Inspect* or ICDAS or Ekstrand or Bitewing or Conventional or Digital or Radiography or Film or Radiogra* or Analo* or Speed* or X Ray or Xray or Radiology or Radiol* or Roentge* or Laser or Fluorescence or Diagnodent or FOTI or DiFOTI or Fiber or Fibre or Transillumination or Optic or Opti* or QLF or Quantit* or Laser or Light or Induced) AND (Validity or Validation or Valid* or Accuracy or Sensitivity or Specificity or SE or SP or ROC or Az or Reproducib* or Reproducibility or Reliability or Reliab* or Kappa or Threshold or Cutoff or Performance or Histolog* or Micro or Micro-computed or CT or *CT) AND (Systemat* or Review or Meta-Analysis or Diagnos* or Diagnost* or Detection or Detect or Detect* or Assessm* or Vivo or Vitro or Study or Studies))

\section{Identification of the relevant literature}

All identified bibliographies (PubMed $N=946$, EMBASE $N=836$ ), including titles and abstracts, were exported to a bibliographic software package (X7.8 for Windows, Thomson Reuters). The imported set of records from each database, including hand searches, was merged into one core database to remove duplicate records and to facilitate retrieval of relevant articles. In the next step, duplicates $(N=696)$ were removed, and the title (and, if needed, the abstract of each bibliography) was checked as to whether it met the inclusion criteria; otherwise, the study was excluded. After the primary identification of includable studies and the removal of duplicates, 1090 records were identified.

\section{Screening and eligibility check}

The titles and abstracts were screened by two reviewers (SK, MJR) independently. The reviewers were not blinded to the names of the authors, institutions, journal or results of each publication. All records were counterchecked in relation to the initially consented inclusion and exclusion criteria. If papers met the inclusion criteria completely or partially, their full-text documents were obtained. Doubts or disagreements were continuously resolved by discussion with an experienced researcher (JK). After review of the titles and abstracts, records that were found to be irrelevant were excluded from further proceedings $(N=894)$. At this step, 196 records were identified for full-text reading. Studies $(N=56)$ that were found to be irrelevant after their full 
texts were read were excluded from further analysis (supplemental Table S0). Finally, 140 studies met the inclusion criteria and were read in detail.

\section{Data collection from the selected studies}

Following the recommendation for diagnostic test accuracy [26], the following relevant items were extracted: study type (in vivo or in vitro studies), study population and teeth (number and age of patients, type and number of permanent teeth used in the study), index test methods (methods, scoring criteria and cut-offs), reference standard method (type of histological validation method, scoring criteria and cutoffs), validity and/or intra- and inter-examiner reliability data for the overall caries detection level (D0 versus D1-D4; Marthaler 1966), dentin caries detection level (D0-2 versus D3-4, Marthaler 1966) [27] and 1/3 dentin caries detection level (D0-2 versus D3-4, Ekstrand et al. 1997) [28]. Two reviewers (SK, MJR) independently extracted the required data from all primary studies. Any doubts or disagreements were continuously resolved by discussion with an experienced researcher (JK) until a consensus was reached. All data were systematically entered into an EpiData database [29] (EpiData software version 2.0.9.57, EpiData Association, Denmark).

\section{RoB assessment}

To date, no suitable set of criteria exists for assessing RoB among caries diagnostic studies. Therefore, existing checklists and proposals [21,30-32] were analysed and adapted to clinical/laboratory caries diagnostic studies. The developed set of criteria includes 16 signalling questions divided into four main domains used for RoB assessments during the review (supplemental Table S7). Using the RoB assessment tool, all included studies were re-evaluated and assessed independently by two reviewers (SK, MJR). An additional and blind assessment was performed by two other colleagues from the workgroup (FE, SM). All RoB assessments are listed in supplemental Tables S8a/b-S13a/b.

In addition to the initially performed systematic search and selection of the literature, all identified papers were further selected according to their RoB status. Here, seven core domains were selected (tooth selection, index test criteria, reference test criteria, incorporation bias, partial verification bias, differential verification bias, bias in the analysis), and each study had to show a low or moderate inclusion in these domains; otherwise, the study was excluded from further analysis. In the next step, the remaining studies were crosschecked for the availability of sufficient validity data reporting cross-tabulation, sensitivity (SE), specificity (SP), positive predictive (PPV), negative predictive values (NPV) or areas under the receiver operating characteristic curve (AUC).

\section{Data handling, statistical procedures and meta-analysis}

All data were entered into a database and later exported to an Excel spreadsheet (Excel 2010, Microsoft Corporation, Redmond, WA, USA). Descriptive analyses were performed using Microsoft Excel 2010 and the statistical package mada version 0.5.9. [33] for RStudio [34]. If the included studies provided contingency tables, the data were used directly. If not, true positives (SE), true negatives (SP), PPV and NPV were calculated from the results in the original publication. If this calculation was not possible, the corresponding study was excluded. Corrections of tables with zero cells were also made; when, for example, the value for the true positives is zero, $R$ itself makes a correction by changing the zero to 0.5 (a very small number) because RStudio cannot deal with zero cells. In some reports, statistical information was given for more than one examiner. However, in those cases, a mean was calculated by logit transformation.

Meta-analytic statistics were calculated for all included diagnostic test methods and commonly used diagnostic thresholds. Diagnostic accuracy and their 95\% confidence intervals $(95 \% \mathrm{CI})$ were calculated from the pooled data from all included studies, in terms of SE, SP and the diagnostic odds ratio (DOR). A bivariate diagnostic random-effects meta-analysis suggested by Reitsma et al. [35] was used to provide pooled estimates of SE and SP for the respective subgroups along with their $95 \%$ CI. This method can take the heterogeneity between studies into account by jointly analysing the logit transformation of SEs and SPs [36]. Finally, the pooled DOR was calculated using a random-effects model following the approach by DerSimonian and Laird [37] and aimed at describing the performance of the included diagnostic tests. An uninformative test shows a DOR value of 1 ; as the DOR increases, the test has more discriminatory power [38]. The area under the curve (AUC) of summary receiver operating characteristics (sROC) was reported to create an overview of the results within each subgroup. The AUC value quantifies the overall ability of a diagnostic test to discriminate between individuals with the disease and those without the disease [39]. The ideal test would have an AUC value of 1 , whereas a random guess would have an AUC of 0.5; the larger the area under the ROC curve, the more accurate the diagnostic test. In addition, sROC plots and forest plots were computed to illustrate the diagnostic performance and heterogeneity, respectively [39]. 


\section{Results}

According to the workflow recommended by the PRISMA guidelines, 140 (108 in vitro and 32 in vivo) studies were initially identified (Fig. 1). After further consideration of the results from the RoB assessment (supplemental Tables S8a/b-S13a/b), an additional 103 publications needed to be excluded due to high RoB or insufficient data reporting (supplemental Tables S8c/d-S13c/d); the summary graphs from the RoB assessment are depicted in Fig. 2. Finally, 29 in vitro and 8 in vivo studies [40-76] were selected according to the described stepwise process and were found to fulfil the inclusion criteria for metaanalysis (Fig. 1, Table 2). Only two studies were identified to use FOTI, and none used QLF.

Meta-analytic validity data are presented for all included caries detection and diagnostic methods in relation to the three chosen caries detection levels for laboratory and clinical studies in Tables 3 and 4, respectively. Most data sets originated from in vitro studies $(N=29$, Table 3) rather than clinical investigations $(N=8$, Table 4$)$. In the in vitro results for all diagnostic methods at the caries detection and dentin caries level, a higher SP than SE value was typically found (Table 3). AUCs were characteristically higher for additional diagnostic methods, e.g. radiography or LF, than for VE. The highest diagnostic performance was observed for $\mathrm{VE}$ at the $1 / 3$ dentin caries detection level (AUC $=0.89)$. The $\mathrm{DOR}$ values ranged from 1.94 to 37.77 (dentin caries detection level/in vitro, Table 3), 2.14 to 60.37 (caries detection level/in vivo, Table 4) and 11.79 to 127.56 (dentin caries detection level/ in vivo, Table 4).

A meta-analysis was conducted for in vivo studies as well (Table 4). Here, SE (0.70) was registered to be higher than SP (0.47) for VE at the caries detection level. The SE (0.72) and SP (0.77) were higher at the $1 / 3$ dentin caries detection level. The meta-analytic diagnostic performance of conventional bitewing radiography (F-speed) and LF was found to be excellent.

In addition to the fact that comparisons between in vitro and in vivo studies should be performed with caution with respect to the imbalance of included studies, a few trends were observed. While on the one hand, the diagnostic performance of VE tended to be higher under laboratory conditions than in clinical settings, on the other hand, the diagnostic performance of VE was not perfect and was lower than that of additional diagnostic methods. Here, conventional radiography (E-speed) and LF measurements showed higher performance data under clinical conditions. Furthermore, for all methods, there seemed to be a tendency towards a higher SE in clinical studies. SP was found to be comparable under laboratory and clinical conditions; only in the case of VE were higher values registered in vitro. Again, full comparisons could not be made due to incompleteness of the data (Tables 3 and 4). In addition, SROC curves and forest plots were computed and are presented in the additional online material (supplemental Tables S14-S17).

\section{Discussion}

This study project summarized the diagnostic accuracy of occlusal caries lesion detection, diagnostic, assessment and/or monitoring methods that were investigated under in vitro and in vivo conditions in permanent, posterior teeth. Therefore, a systematic search of the literature was conducted; potential sources of bias were considered; and finally, a meta-analysis was performed to compare commonly used caries diagnostic methods instead of analysing each method separately [12-16, 77-81]. When considering the quantity and quality of the systematically searched literature, it should be noted that there was a remarkable reduction in includable studies with each additional selection step (Fig. 1). Finally, 37 studies were included in the metaanalysis [40-76], and unfortunately, these studies were not equally distributed over all test methods, study setups and considered thresholds (Tables 2, 3 and 4). Most studies were conducted under laboratory conditions (Fig. 1, Table 2) and investigated the diagnostic accuracy using the dentin caries detection threshold (Tables 3 and 4). VE, BWR and LF were tested most frequently than other additional diagnostic methods. This heterogenetic information pattern suggests that it is substantially necessary to conduct caries diagnostic studies that include different test methods and thresholds on pits and fissures. This demand is even more crucial for clinical studies.

The diverging methodology of each trial-technologies, thresholds, index and reference test criteria (supplemental Tables S1-S6)-and several sources of bias (Fig. 2, supplemental Tables S7-S13b) resulted in the exclusion of numerous studies, which ultimately lowered the number of includable studies and illustrated the heterogeneity between studies. This fact underlines the need for standardization and the necessity to conduct well-designed and well-powered caries diagnostic and detection studies in the future.

Regarding the meta-analytic diagnostic performance of the included diagnostic methods (Tables 3 and 4), it must be emphasized that for some methods, only a limited number of studies were identified. Exceptions were VE, BWR and LF (Tables 3 and 4). When viewing these data, a few trends can be discussed, but it should be mentioned from the outset that the results of this meta-analysis should not be overrated due to the limited number of includable studies for each of the relevant caries detection categories (Table 2). Nevertheless, 


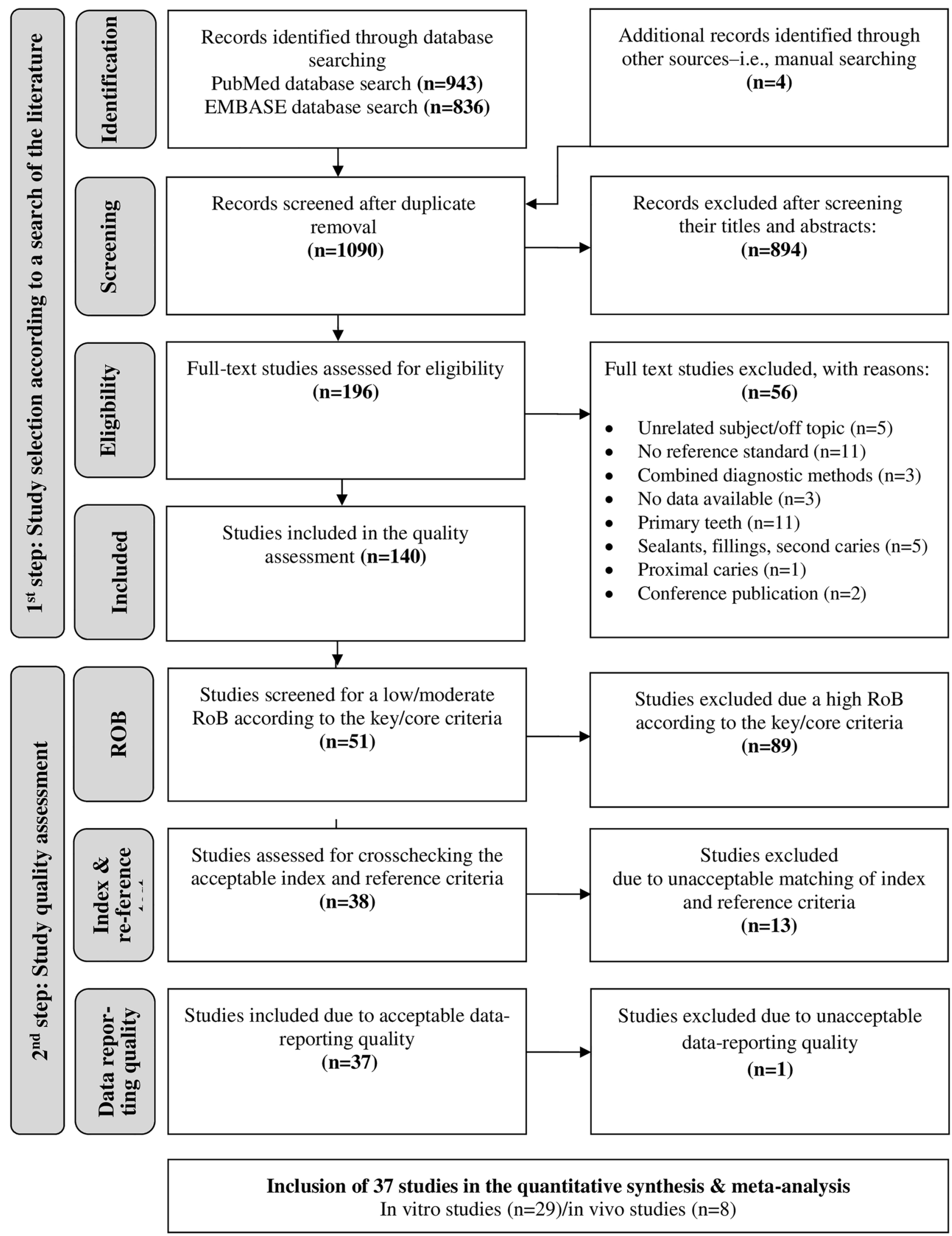

Fig. 1 Flow diagram detailing our search and study selection process applied during the systematic literature search (1st step) and study quality assessment (2nd step) 
Fig. 2 RoB graph across included in vivo (A) and in vitro (B) caries diagnostic studies for occlusal surfaces. Item no 1 (patient selection bias) is only available for clinical diagnostic studies

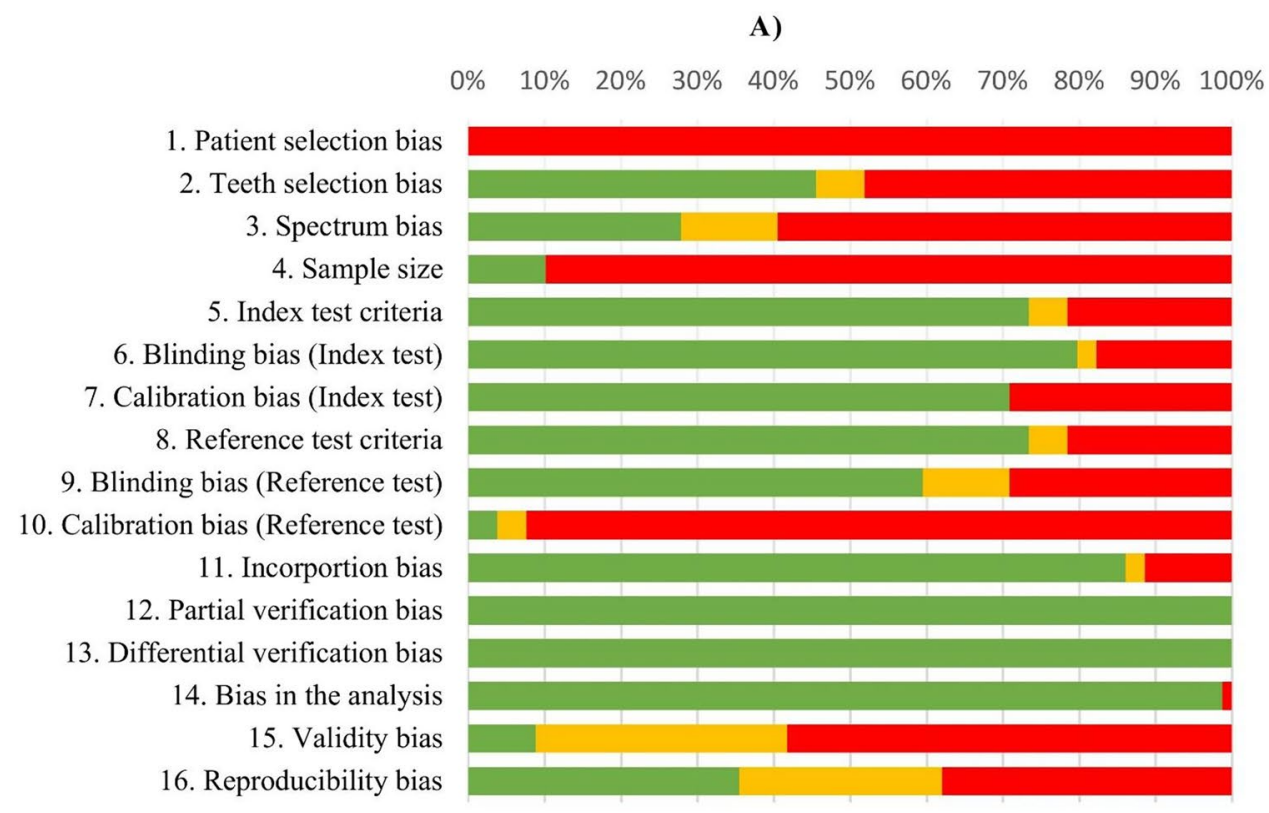

B)

$\begin{array}{llllllllllll}0 \% & 10 \% & 20 \% & 30 \% & 40 \% & 50 \% & 60 \% & 70 \% & 80 \% & 90 \% & 100 \%\end{array}$

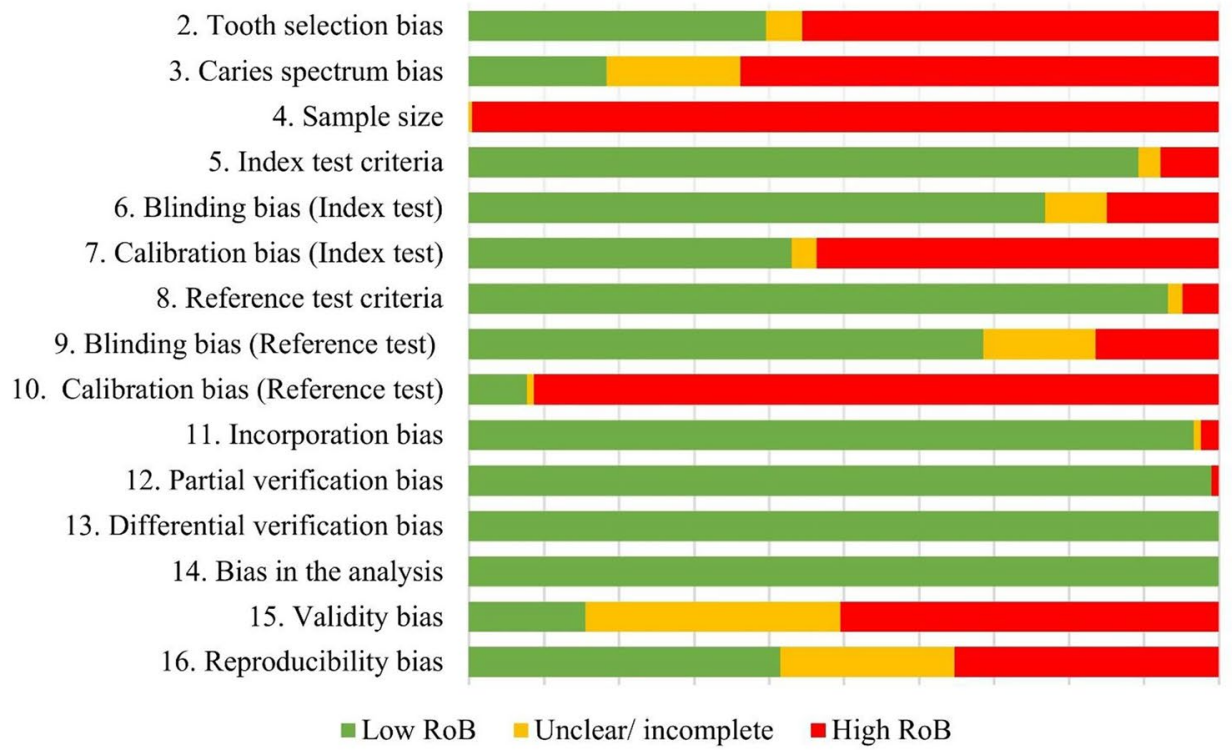

2. Tooth selection bias spectrum bias

6. Blinding bias (Index test)

Calibration bias (Index test)

8. Reference test criteria

9. Blinding bias (Reference test)

10. Calibration bias (Reference test)

11. Incorporation bias

12. Partial verification bias

4. Bias in the analysis

15. Validity bias

Low RoB

a few conclusions can be drawn from the available data. The data support the generally and repeatedly published assumption that VE of pits and fissures is not perfect and needs to be accompanied by additional diagnostic methods. Nevertheless, more recently published criteria (ICDAS, UniViSS) that summarize the whole spectrum of non-cavitated caries lesions may help to overcome this drawback [16, 82-84]. Under in vitro conditions, VE showed mostly high SP values, while SE varied between the different methods and thresholds. A large difference between SE values was registered for VE under in vitro and in vivo conditions (Tables 3 and 4), which was also reported by Gimenez et al. [15].
Therefore, VE under in vitro conditions results in higher SP values. Vice versa, clinical evaluations probably include more details, which may result in higher diagnostic SE values especially for enamel caries.

It should be further noted that VE is the method that enables the clinician to collect important diagnostic covariables, e.g. presence of biofilm or lesion appearance, enables differential diagnoses and provides finally information about the caries lesions activity $[85,86]$. The latter aspect potentially influences the individual caries management strategy and it's consideration has become mandatory in clinical practice [87-89]. Contrary, with respect to the 
Table 2 Overview of the identified diagnostic studies in relation to the method used and characteristics of the study set-up with stepwise included studies for meta-analysis

\begin{tabular}{|c|c|c|c|c|c|}
\hline \multicolumn{3}{|l|}{1 st step } & \multicolumn{3}{|l|}{ 2nd step } \\
\hline \multicolumn{3}{|c|}{ Study inclusion according to the systematic search of the literature } & \multicolumn{3}{|c|}{$\begin{array}{l}\text { Study inclusion according to the quality assess- } \\
\text { ment }\end{array}$} \\
\hline Studies on diagnostic methods & Study set-up & $\begin{array}{l}\text { Specification (N according to } \\
\text { PRISMA) }\end{array}$ & $\begin{array}{l}\text { Low/ } \\
\text { moderate } \\
\text { RoB }\end{array}$ & $\begin{array}{l}\text { Acceptable index } \\
\text { and reference test }\end{array}$ & $\begin{array}{l}\text { Acceptable data } \\
\text { reporting quality }\end{array}$ \\
\hline \multirow[t]{2}{*}{$\operatorname{VE}(N=106)$} & In vivo $(N=27)$ & $\begin{array}{l}\text { Without a probe }(N=22) \\
\text { With a probe }(\mathrm{N}=5)\end{array}$ & 10 & 4 & 3 \\
\hline & In vitro $(N=79)$ & $\begin{array}{l}\text { Without a probe }(N=66) \\
\text { With a probe }(N=13)\end{array}$ & 23 & 14 & 13 \\
\hline \multirow{8}{*}{$\begin{array}{l}\text { Conventional bitewing radiography } \\
(N=63)\end{array}$} & In vivo $(N=18)$ & D-speed $(N=10)$ & 3 & 2 & 1 \\
\hline & & E-speed $(N=3)$ & 2 & 2 & 2 \\
\hline & & F-speed $(N=1)$ & - & - & - \\
\hline & & Not specified $(N=4)$ & 1 & - & - \\
\hline & In vitro $(N=45)$ & D-speed $(N=13)$ & 4 & 3 & 3 \\
\hline & & E-speed $(N=24)$ & 5 & 2 & 2 \\
\hline & & F-speed $(N=6)$ & 2 & 2 & 2 \\
\hline & & Not specified $(N=7)$ & 1 & 1 & 1 \\
\hline \multirow{6}{*}{$\begin{array}{l}\text { Digital bitewing radiography } \\
\qquad(N=19)\end{array}$} & In vivo $(N=3)$ & Sensor $(N=0)$ & - & - & - \\
\hline & & Phosphor plate $(N=1)$ & - & - & - \\
\hline & & Not specified $(N=2)$ & 1 & - & - \\
\hline & In vitro $(N=16)$ & Sensor $(N=9)$ & 3 & 2 & 2 \\
\hline & & Phosphor plate $(N=8)$ & 2 & 1 & 1 \\
\hline & & Not specified $(N=0)$ & - & - & - \\
\hline \multirow[t]{4}{*}{ LF measurement $(N=68)$} & In vivo $(N=22)$ & DIAGNOcam $2095(N=22)$ & 9 & 3 & 3 \\
\hline & & DIAGNOcam 2190/Pen $(N=5)$ & 2 & - & - \\
\hline & In vitro $(N=46)$ & DIAGNOcam $2095(N=38)$ & 18 & 10 & 10 \\
\hline & & DIAGNOcam 2190/Pen $(N=12)$ & 7 & 6 & 5 \\
\hline \multirow[t]{2}{*}{ Fibre-optic transillumination $(N=8)$} & In vivo $(N=1)$ & & - & - & - \\
\hline & In vitro $(N=7)$ & & 3 & 3 & 3 \\
\hline \multirow{2}{*}{$\begin{array}{l}\text { Quantitative light-induced fluores- } \\
\text { cence }(N=7)\end{array}$} & In vivo $(N=1)$ & & 1 & - & - \\
\hline & In vitro $(N=6)$ & & 2 & - & - \\
\hline
\end{tabular}

methodological difficulties and missing standards to validate caries activity, it was decided to exclude the activity assessment from the present systematic search of literature and meta-analysis.

In vitro data from Ekstrand and co-workers [28, 90, 91] pointed to the fact that non-cavitated occlusal lesions depth (histological assessed), either, was restricted to the enamel or penetrated the dentin, but then restricted to the outer $1 / 3$ towards the pulp. To raise the accuracy, e.g. in terms of SE and SP, Ekstrand et al. [28] suggested to move the standard thresholds - enamel versus dentin caries - to lesions reaching the middle or inner $1 / 3$ of the dentin. Thus, combined SP and SP values amounted to 175 [91]. The new threshold is much more relevant to the clinicians than the old one, as noncavitated lesions without an obvious shadow should receive non-operative care if the lesions are assessed as active, while more mature active lesions should receive operative [16].

BWR is the most commonly used additional caries lesion detection method in daily dental practice. However, its validity on occlusal surfaces is often questioned, especially in the early stages of caries [92]. Here, the anatomy of the tooth crown results in superimposed images on the twodimensional (bitewing) radiographs, making the detection of early dentin caries lesions harder in comparison to that on proximal sides [93]. Surprisingly, the results of the present meta-analysis did not show a striking difference in SE and SP values between different $\mathrm{X}$-ray types assessed in this review. However, the difference in accuracy parameters was obvious compared to those of LF. However, due to the limited number of studies belonging to each BWR category, 
Table 3 Bivariate diagnostic random-effects meta-analysis for the finally included in vitro studies for all diagnostic methods at different caries detection levels

\begin{tabular}{|c|c|c|c|c|}
\hline \multirow[t]{2}{*}{ Meta-analytical diagnostic performance } & & \multicolumn{3}{|l|}{ In vitro } \\
\hline & & Caries detection level & Dentin detection level & $1 / 3$ dentin detection level \\
\hline $\mathrm{VE}$ & $\begin{array}{l}\text { N } \\
\text { SE }(95 \% \mathrm{CI}) \\
\text { SP }(95 \% \mathrm{CI}) \\
\text { AUC (Reitsma) } \\
\text { DOR }\end{array}$ & $\begin{array}{l}3 \\
0.59(0.52-0.67) \\
0.83(0.70-0.92) \\
0.59 \\
5.55(1.88-16.38)\end{array}$ & $\begin{array}{l}8 \\
0.46(0.20-0.73) \\
0.87(0.72-0.95) \\
0.79 \\
5.93(3.11-11.31)\end{array}$ & $\begin{array}{l}2 \\
0.69(0.51-0.82) \\
0.88(0.83-0.92) \\
0.89 \\
16.6(4.85-56.79)\end{array}$ \\
\hline Conventional bitewing radiography (D-speed) & $\begin{array}{l}\mathrm{N} \\
\text { SE }(95 \% \mathrm{CI}) \\
\text { SP }(95 \% \mathrm{CI}) \\
\text { AUC (Reitsma) } \\
\text { DOR }\end{array}$ & - & $\begin{array}{l}1 \\
0.42(0.18-0.69) \\
0.73(0.53-0.87) \\
0.60 \\
1.94(0.46-8.17)\end{array}$ & - \\
\hline Conventional bitewing radiography (E-speed) & $\begin{array}{l}\mathrm{N} \\
\text { SE }(95 \% \mathrm{CI}) \\
\text { SP }(95 \% \mathrm{CI}) \\
\text { AUC (Reitsma) } \\
\text { DOR }\end{array}$ & - & $\begin{array}{l}2 \\
0.48(0.21-0.77) \\
0.95(0.53-0.997) \\
0.75 \\
10.69(3.67-31.15)\end{array}$ & - \\
\hline Conventional bitewing radiography (F-speed) & $\begin{array}{l}\mathrm{N} \\
\text { SE }(95 \% \mathrm{CI}) \\
\text { SP }(95 \% \mathrm{CI}) \\
\text { AUC (Reitsma) } \\
\text { DOR }\end{array}$ & - & $\begin{array}{l}2 \\
0.50(0.22-0.79) \\
0.97(0.71-0.998) \\
0.82 \\
23.60(8.28-67.24)\end{array}$ & - \\
\hline Digital bitewing radiography (phosphor plates) & $\begin{array}{l}\mathrm{N} \\
\text { SE }(95 \% \mathrm{CI}) \\
\text { SP }(95 \% \mathrm{CI}) \\
\text { AUC (Reitsma) } \\
\text { DOR }\end{array}$ & - & $\begin{array}{l}2 \\
0.48(0.24-0.73) \\
0.95(0.59-0.995) \\
0.73 \\
15.57(0.47-515.27)\end{array}$ & - \\
\hline LF 2095 & $\begin{array}{l}\text { N } \\
\text { SE }(95 \% \mathrm{CI}) \\
\text { SP }(95 \% \mathrm{CI}) \\
\text { AUC (Reitsma) } \\
\text { DOR }\end{array}$ & $\begin{array}{l}6 \\
0.75(0.58-0.86) \\
0.76(0.60-0.87) \\
0.81 \\
10.28(4.35-24.28)\end{array}$ & $\begin{array}{l}7 \\
0.68(0.54-0.79) \\
0.78(0.68-0.85) \\
0.79 \\
8.01(4.04-15.88)\end{array}$ & - \\
\hline LF pen 2190 & $\begin{array}{l}\mathrm{N} \\
\text { SE }(95 \% \mathrm{CI}) \\
\text { SP }(95 \% \mathrm{CI}) \\
\text { AUC (Reitsma) } \\
\text { DOR }\end{array}$ & $\begin{array}{l}2 \\
0.78(0.44-0.94) \\
0.77(0.62-0.87) \\
0.77 \\
11.83(2.66-52.63)\end{array}$ & $\begin{array}{l}4 \\
0.63(0.37-0.83) \\
0.77(0.62-0.88) \\
0.78 \\
5.85(1.77-19.30)\end{array}$ & - \\
\hline Fibre-optic transillumination FOTI & $\begin{array}{l}\mathrm{N} \\
\text { SE }(95 \% \mathrm{CI}) \\
\text { SP }(95 \% \mathrm{CI}) \\
\text { AUC (Reitsma) } \\
\text { DOR }\end{array}$ & $\begin{array}{l}1 \\
0.97(-0.92-0.99) \\
0.50(0.34-0.66) \\
0.92 \\
38.33(10.15-144.77)\end{array}$ & $\begin{array}{l}2 \\
0.49(0.20-0.79) \\
0.97(0.89-0.994) \\
0.92 \\
37.77(13.69-104.19)\end{array}$ & - \\
\hline
\end{tabular}

these results should be interpreted with caution. Unlike previously published reviews [13], this review considered separate studies using conventional film-based BWR and digital BWR (including their different modalities) with the aim of reducing bias. Unfortunately, this approach resulted in a low number of includable studies in each category.

LF has been used as an adjunct caries detection method for incipient lesions that otherwise could not be detected by VE alone [94]. The results of our study revealed high SE and SP values for LF under in vitro conditions, which is in line with previously reported findings by Gimenez et al. [14] and Rosa et al. [12]. When considering the small number of includable data from in vivo studies (Table 4), these data should be treated with caution, but they are still comparable to previous findings from Pinheiro et al. [94]. In contrast to these reassuring results, LF alone is not sufficient for the correct diagnosis of caries and good standardization is essential to avoid overtreatment and false-positive readings due to other fluorescence sources [12, 14, 81, 84, 94].

The present study has strengths and limitations. First, one strength is that commonly used diagnostic methods for occlusal caries detection and diagnostics were analysed in one meta-analysis. Second, there was a strict study selection protocol, which was based on principles 
Table 4 Bivariate diagnostic random-effects meta-analysis for the finally included in vivo studies for all diagnostic methods at different caries detection levels

\begin{tabular}{|c|c|c|c|c|}
\hline \multirow[t]{2}{*}{ Meta-analytical diagnostic performance } & & \multicolumn{3}{|l|}{ In vivo } \\
\hline & & Caries detection level & Dentin detection level & $1 / 3$ dentin detection level \\
\hline VE & $\begin{array}{l}\text { N } \\
\text { SE }(95 \% \mathrm{CI}) \\
\text { SP }(95 \% \mathrm{CI}) \\
\text { AUC (Reitsma) } \\
\text { DOR }\end{array}$ & $\begin{array}{l}2 \\
0.70(0.59-0.80) \\
0.47(0.26-0.70) \\
0.70 \\
2.14(0.73-6.28)\end{array}$ & - & $\begin{array}{l}3 \\
0.72(0.52-0.86) \\
0.77(0.67-0.85) \\
0.77 \\
10.18(3.94-26.29)\end{array}$ \\
\hline Conventional bitewing radiography (D-speed) & $\begin{array}{l}\text { N } \\
\text { SE }(95 \% \text { CI }) \\
\text { SP }(95 \% \text { CI }) \\
\text { AUC (Reitsma) } \\
\text { DOR }\end{array}$ & $\begin{array}{l}1 \\
0.65(0.57-0.73) \\
0.58(0.42-0.72) \\
0.65 \\
2.59(1.24-5.44)\end{array}$ & $\begin{array}{l}2 \\
0.79(0.41-0.96) \\
0.75(0.68-0.82) \\
0.77 \\
11.79(2.43-57.24)\end{array}$ & - \\
\hline Conventional bitewing radiography (E-speed) & $\begin{array}{l}\text { N } \\
\text { SE }(95 \% \text { CI }) \\
\text { SP (95\% CI) } \\
\text { AUC (Reitsma) } \\
\text { DOR }\end{array}$ & $\begin{array}{l}1 \\
0.80(0.71-0.87) \\
0.94(0.46-0.996) \\
0.94 \\
60.37(3.31 \vee 1100.70)\end{array}$ & $\begin{array}{l}2 \\
0.76(0.61-0.87) \\
0.98(0.79-0.998) \\
0.90 \\
127.56(7.38-2203.70)\end{array}$ & - \\
\hline Conventional bitewing radiography (F-speed) & $\begin{array}{l}\text { N } \\
\text { SE }(95 \% \text { CI }) \\
\text { SP }(95 \% \text { CI }) \\
\text { AUC (Reitsma) } \\
\text { DOR }\end{array}$ & - & - & - \\
\hline Digital bitewing radiography & $\begin{array}{l}\text { N } \\
\text { SE }(95 \% \mathrm{CI}) \\
\text { SP }(95 \% \mathrm{CI}) \\
\text { AUC (Reitsma) } \\
\text { DOR }\end{array}$ & - & - & - \\
\hline LF 2095 & $\begin{array}{l}\text { N } \\
\text { SE }(95 \% \mathrm{CI}) \\
\text { SP (95\% CI) } \\
\text { AUC (Reitsma) } \\
\text { DOR }\end{array}$ & $\begin{array}{l}1 \\
0.88(0.81-0.93) \\
0.71(0.55-0.83) \\
0.88 \\
18.33(7.57-44.37)\end{array}$ & $\begin{array}{l}2 \\
0.91(0.86-0.95) \\
0.78(0.46-0.94) \\
0.92 \\
35.90(13.43-96.00)\end{array}$ & - \\
\hline LF pen 2190 & $\begin{array}{l}\text { N } \\
\text { SE }(95 \% \text { CI }) \\
\text { SP (95\% CI) } \\
\text { AUC (Reitsma) } \\
\text { DOR }\end{array}$ & - & - & - \\
\hline Fibre-optic transillumination FOTI & $\begin{array}{l}\text { N } \\
\text { SE }(95 \% \text { CI }) \\
\text { SP }(95 \% \text { CI }) \\
\text { AUC (Reitsma) } \\
\text { DOR }\end{array}$ & - & - & - \\
\hline
\end{tabular}

for performing systematic reviews and, in addition, a tailored RoB assessment that included only studies with a low RoB and excluded probable heterogenic publications. Third, the present study considered different thresholds independently for in vitro and in vivo studies. As a main limitation of the study selection process used, the exclusion of reports with a potentially high RoB from the meta-analysis and feasibly subjectivity of included selection criteria might be discussed for very low number of the included studies, especially in the clinical research. To our knowledge, such strict selection has not previously been performed because it is not part of the current recommendations for conducting a meta-analysis. While this step may result in the analysis of a homogenous pool of studies, it resulted, by contrast, in a substantial reduction in includable studies. It is further worth mentioning that several reports needed extensive discussion with respect to missing data or information. Therefore, the inclusion or exclusion of a single study remained in some cases a subjective procedure that could not be fully objectified. Because of the limited number of includable studies and the low sample size, the results from this meta-analysis should be interpreted with caution. This fact underlines the urgent need for well-designed and well-powered 
diagnostic studies that use multiple diagnostic procedures and different caries thresholds.

\section{Conclusions}

There is an overall need for high-quality, well-designed and standardized studies on the detection, diagnosis, assessment and/or monitoring of occlusal surface caries. This need must be emphasized for diagnostic studies under in vivo conditions due to the limited number of clinical trials and the documented heterogeneity between published reports. When considering the meta-analytic results, VE, BWR and LF provide acceptable measures for their diagnostic performance on occlusal surfaces. Again, the present results should be interpreted with caution with respect to the limited data in many diagnostic categories.

Supplementary Information The online version contains supplementary material available at https://doi.org/10.1007/s00784-021-04024-1.

Funding Open Access funding enabled and organized by Projekt DEAL. This project was funded by a grant for creating a scientific network obtained from the German Research Foundation (Deutsche Forschungsgemeinschaft, SCHU-3217/1-1).

\section{Declarations}

Ethics approval This article does not contain any animal or human studies performed by any of the authors.

Informed consent For this type of study, formal consent is not required.

Conflicts of interest Svetlana Kapor declares that she has no conflicts of interest. Mila Janic Rankovic declares that she has no conflicts of interest. Alexander Crispin declares that he has no conflicts of interest. Yegane Khazaei declares that she has no conflicts of interest. Ina Schüler declares that she has no conflicts of interest. Felix Krause declares that he has no conflicts of interest. Kim Ekstrand declares that he has no conflicts of interest. Stavroula Michou declares that she has no conflicts of interest. Klaus Neuhaus declares that he has no conflicts of interest. Florin Eggmann declares that he has no conflicts of interest. Adrian Lussi declares that he has no conflicts of interest. MarieCharlotte Huysmans declares that she has no conflicts of interest. Jan Kühnisch declares that he has no conflicts of interest. All applicable international, national and/or institutional recommendations for conducting systematic revisions were followed.

Open Access This article is licensed under a Creative Commons Attribution 4.0 International License, which permits use, sharing, adaptation, distribution and reproduction in any medium or format, as long as you give appropriate credit to the original author(s) and the source, provide a link to the Creative Commons licence, and indicate if changes were made. The images or other third party material in this article are included in the article's Creative Commons licence, unless indicated otherwise in a credit line to the material. If material is not included in the article's Creative Commons licence and your intended use is not permitted by statutory regulation or exceeds the permitted use, you will need to obtain permission directly from the copyright holder. To view a copy of this licence, visit http://creativecommons.org/licenses/by/4.0/.

\section{References}

1. Weerheijm KL, Groen HJ, Bast AJJ, Kieft JA, Eijkman MAJ, Van Amerongen WE (1992) Clinically undetected occlusal dentine caries: a radiographic comparison. Caries Res 26(4):305-309. https://doi.org/10.1159/000261457

2. Weerheijm KL, Kidd EAM, Groen HJ (1997) The effect of fluoridation on the occurrence of hidden caries in clinically sound occlusal surfaces. Caries Res 31(1):30-34. https://doi.org/10. $1159 / 000262370$

3. Ricketts D, Kidd E, Weerheijm K, de Soet H (1997) Hidden caries: what is it? Does it exist? Does it matter? Int Dent J 47(5):259-265. https://doi.org/10.1002/j.1875-595x.1997.tb007 86. $\mathrm{X}$

4. Zadik Y, Bechor R (2008) Hidden Occlusal Caries. NY State Dent J 74(4):46-50

5. Kühnisch J, Galler M, Seitz M, Stich H, Lussi A, Hickel R, Bücher $\mathrm{K}$ (2012) Irregularities below the enamel-dentin junction may predispose for fissure caries. J Dent Res 91(11):1066-1070. https:// doi.org/10.1177/0022034512458688

6. Trevisan TC, de Andrade MC, Presoto CD, Júnior OB, Andrade MF, Bortolatto JF (2015) Hidden caries: A critical review. Sci J Dent 2(1):33-36. https://doi.org/10.15713/ins.sjod.20

7. Mohanraj M, Prabhu VR, Senthil R (2016) Diagnostic methods for early detection of dental caries-A review. Int J Pedod Rehabil 1(1):29-36

8. Neuhaus KW, Lussi A (2018) Carious Lesion Diagnosis: Methods, Problems, Thresholds. In: Schwendicke F, Frencken J, Innes N (eds) Caries Excavation. Evolution of Treating Cavitated Carious Lesions. Karger, Basel, vol. 27, pp. 24-31. https://doi.org/10. 1159/000487828

9. Ismail AI, Pitts NB, Telle M (2015) The international caries classification and management system (ICCMS) an example of a caries management pathway. BMC Oral Health 15(1):S9. https://doi. org/10.1186/1472-6831-15-S1-S9

10. Kühnisch J, Söchtig F, Pitchika V, Laubender R, Neuhaus KW, Lussi A, Hickel R (2016) In vivo validation of near-infrared light transillumination for interproximal dentin caries detection. Clin Oral Investig 20(4):821-829. https://doi.org/10.1007/ s00784-015-1559-4

11. Pretty IA, Ekstrand KR (2016) Detection and monitoring of early caries lesions: a review. Eur Arch Paediatr Dent 17(1):13-25. https://doi.org/10.1007/s40368-015-0208-6

12. Rosa MI, Schambeck VS, Dondossola ER, Alexandre MC, Tuon L, Grande AJ, Hugo F (2016) Laser fluorescence of caries detection in permanent teeth in vitro: a systematic review and metaanalysis. J Evid Based Med 9(4):213-224. https://doi.org/10.1111/ jebm. 12227

13. Schwendicke F, Tzschoppe M, Paris S (2015) Radiographic caries detection: A systematic review and meta-analysis. J Dent 43(8):924-933. https://doi.org/10.1016/j.jdent.2015.02.009

14. Gimenez T, Piovesan C, Braga MM, Raggio DP, Deery C, Ricketts DN, Ekstrand KR, Mendes FM (2015) Visual Inspection for Caries Detection: A Systematic Review and Meta-analysis. J Dent Res 94(7):895-904. https://doi.org/10.1177/0022034515586763

15. Gimenez T, Piovesan C, Braga MM, Raggio DP, Deery C, Ricketts DN, Ekstrand KR, Mendes FM (2015) Clinical relevance of studies on the accuracy of visual inspection for detecting caries lesions: a systematic review. Caries Res 49(2):91-98. https://doi. org/10.1159/000365948

16. Ekstrand KR, Gimenez T, Ferreira FR, Mendes FM, Braga MM (2018) The international caries detection and assessment system - ICDAS: a systematic review. Caries Res 52(5):406-419. https:// doi.org/10.1159/000486429 
17. Whiting P, Rutjes AW, Reitsma JB, Bossuyt PM, Kleijnen J (2003) The development of QUADAS: a tool for the quality assessment of studies of diagnostic accuracy included in systematic reviews. BMC Med Res Methodol 3:25. https://doi.org/10.1186/ 1471-2288-3-25

18. Whiting PF, Rutjes AW, Westwood ME, Mallett S, Deeks JJ, Reitsma JB, Leeflang MM, Sterne JA, Bossuyt PM (2011) QUADAS-2: a revised tool for the quality assessment of diagnostic accuracy studies. Ann Intern Med 155(8):529-536. https://doi. org/10.7326/0003-4819-155-8-201110180-00009

19. Deeks JJ, Bossuyt PM, Gatsonis C (2013) Cochrane Handbook for Systematic Reviews of Diagnostic Test Accuracy. 1.0.0 edition. The Cochrane Collaboration. Available from: http://srdta. cochrane.org/. Accessed May $17^{\text {th }}, 2021$

20. McInnes MDF, Moher D, Thombs BD, McGrath TA, Bossuyt PM, Clifford T, Cohen JF, Deeks JJ, Gatsonis C, Hooft L, Hunt HA, Hyde CJ, Korevaar DA, Leeflang MMG, Macaskill P, Reitsma JB, Rodin R, Rutjes AWS, Salameh JP, Stevens A, Takwoingi Y, Tonelli M, Weeks L, Whiting P, Willis BH (2018) Preferred Reporting Items for a Systematic Review and Metaanalysis of Diagnostic Test Accuracy Studies: The PRISMADTA Statement. JAMA 319(4):388-396. https://doi.org/10. 1001/jama.2017.19163

21. Campbell JM, Klugar M, Ding S, Carmody DP, Hakonsen SJ, Jadotte YT, White S, Munn Z (2015) Diagnostic test accuracy: methods for systematic review and meta-analysis. Int J Evid Based Health 13(3):154-162. https://doi.org/10.1097/XEB. 0000000000000061

22. Costa AM, Bezzerra AC, Fuks AB (2007) Assessment of the accuracy of visual examination, bite-wing radiographs and DIAGNOdent on the diagnosis of occlusal caries. Eur Arch Paediatr Dent 8(2):118-122. https://doi.org/10.1007/BF032 62580

23. Huysmans MC, Longbottom C (2004) The challenges of validating diagnostic methods and selecting appropriate gold standards. J Dent Res 83(1):48-52. https://doi.org/10.1177/154405910408301 s10

24. Wenzel A, Hintze H (1999) The choice of gold standard for evaluating tests for caries diagnosis. Dentomaxillofac Radiol 28(3):132-136. https://doi.org/10.1259/dmfr.28.3.10740465

25. Moher D, Liberati A, Tetzlaff J (2009) Preferred reporting items for systematic reviews and meta-analysis: the PRISMA statement. Plos Med 6(7):e1000097. https://doi.org/10.1371/journal.pmed. 1000097

26. Macaskill P, Gatsonis C, Deeks JJ, Harbord RM, Takwoingi Y (2010) Chapter 10: Analysing and Presenting Results. In: Deeks JJ, Bossuyt PM, Gatsonis C (eds). Cochrane Handbook for Systematic Reviews of Diagnostic Test Accuracy Version 1.0. The Cochrane Collaboration. Available from: http://srdta.cochrane. org/. Accessed May $17^{\text {th }}, 2021$

27. Marthaler TM (1966) Partial recording of dental caries in incidence studies. Adv Fluorine Res 4:41-52

28. Ekstrand KR, Ricketts DNJ, Kidd EAM (1997) Reproducibility and accuracy of three methods for assessment of demineralization depth on the occlusal surface: an in vitro examination. Caries Res 31(3):224-231

29. Lauritsen JM (2000-2008) EpiData Data Entry, Data Management and basic Statistical Analysis System. Odense Denmark, EpiData Association. Available from http://www.epidata.dk. Accessed May $17^{\text {th }}, 2021$

30. Reitsma JB, Rutjes AWS, Whiting P, Vlassov VV, Leeflang MMG, Deeks JJ (2009) Chapter 9: assessing methodological quality. In: Deeks JJ, Bossuyt PM, Gatsonis C (eds). Cochrane handbook for systematic reviews of diagnostic test accuracy version 1.0.0: The Cochrane Collaboration; 2009. Available from: http://srdta.cochr ane.org/. Accessed May $17^{\text {th }}, 2021$
31. Viswanathan M, Patnode CD, Berkman ND et al (2017) Assessing the risk of bias in systematic reviews of health care interventions. In: Methods Guide for Effectiveness and Comparative Effectiveness Reviews. Rockville (MD): AHRQ Publication No. 17(18)-EHC036-EF. Rockville, MD: Agency for Healthcare Research and Quality; December 2017. Posted final reports are located on the Effective Health Care Program search page. https:// doi.org/10.23970/AHRQEPCMETHGUIDE2. Accessed May $17^{\text {th }}, 2021$

32. Whiting P, Savović J, Higgins JP, Caldwell DM, Reeves BC, Shea B, Churchill R (2016) ROBIS: a new tool to assess risk of bias in systematic reviews was developed. J Clin Epidemiol 69:225-234

33. Doebler P (2019) Meta-Analysis of Diagnostic Accuracy. R package version 0.5.9. Available from: https://CRAN.R-project.org/ package $=$ mada. Accessed May $17^{\text {th }}, 2021$

34. RStudio Team (2018) RStudio: Integrated development for R. RStudio Inc, Boston, MA Available from: http://www.rstudio. $\mathrm{com} /$. Accessed May $17^{\text {th }}, 2021$

35. Reitsma JB, Glas AS, Rutjes AW, Scholten RJ, Bossuyt PM, Zwinderman AH (2005) Bivariate analysis of sensitivity and specificity produces informative summary measures in diagnostic reviews. J Clin Epidemiol 58(10):982-990. https://doi.org/10.1016/j.jclin epi.2005.02.022

36. Chu H, Guo H, Zhou Y (2010) Bivariate random effects metaanalysis of diagnostic studies using generalized linear mixed models. Med Decis Making 30(4):499-508. https://doi.org/10.1177/ 0272989x09353452

37. DerSimonian R, Laird N (1986) Meta-analysis in clinical trials. Control Clin Trials 7(3):177-188. https://doi.org/10.1016/01972456(86)90046-2

38. Macaskill P GC, Deeks JJ, Harbord RM, Takwoingi Y (2010) Chapter 10: Analysing and Presenting Results. In: Deeks JJ, Bossuyt PM, Gatsonis C (eds), Cochrane Handbook for Systematic Reviews of Diagnostic Test Accuracy Version 1.0. The Cochrane Collaboration. Available from: http://srdta.cochrane. org/. Accessed May $17^{\text {th }}, 2021$

39. Bossuyt P, Davenport C, Deeks J, Hyde C, Leeflang M, Scholten $R(2013)$ Chapter 11. Interpreting results and drawing conclusions. In: Deeks JJ, Bossuyt PM, Gatsonis C (eds) Cochrane Handbook for Systematic Reviews of Diagnostic Test Accuracy Version 092013. Available from: http://srdta.cochrane.org/ Accessed: May $17^{\text {th }}, 2021$

40. Nytun RB, Raadal M, Espelid I (1992) Diagnosis of dentin involvement in occlusal caries based on visual and radiographic examination of the teeth. Scandinavian J of Dent Res 100(3):144 148. https://doi.org/10.1111/j.1600-0722.1992.tb01730.x

41. Ketley CE, Holt RD (1993) Visual and radiographic diagnosis of occlusal caries in first permanent molars and in second primary molars. Br Dent J 174(10):364-370. https://doi.org/10.1038/sj. bdj. 4808172

42. Lussi A (1993) Comparison of different methods for the diagnosis of fissure caries without cavitation. Caries Res 27(5):409-416. https://doi.org/10.1159/000261572

43. Deery C, Fyffe HE, Nugent Z, Nuttall NM, Pitts NB (1995) The Effect of Placing a Clear Pit and Fissure Sealant on the Validity and Reproducibility of Occlusal Caries Diagnosis. Caries Res 29(5):377-381. https://doi.org/10.1159/000262096

44. Ie YL, Verdonschot EH, Schaeken MJ, van't Hof MA, (1995) Electrical conductance of fissure enamel in recently erupted molar teeth as related to caries status. Caries Res 29(2):94-99. https:// doi.org/10.1159/000262048

45. Ricketts DN, Kidd EA, Smith BG, Wilson RF (1995) Clinical and radiographic diagnosis of occlusal caries: a study in vitro. J Oral Rehabil 22(1):15-20. https://doi.org/10.1111/j.1365-2842.1995. tb00205.x 
46. Gray GB, Paterson RC (1997) Fissure caries diagnosis and resulting treatment decisions by clinical community dental officers and general dental practitioners. Eur J Prosthodont Restor Dent 5(1):23-29

47. Cortes DF, Ekstrand KR, Elias-Boneta AR, Ellwood RP (2000) An in vitro comparison of the ability of fibre-optic transillumination, visual inspection and radiographs to detect occlusal caries and evaluate lesion depth. Caries Res 34(6):443-447. https://doi. org/10.1159/000016621

48. Pereira AC, Verdonschot EH, Huysmans MC (2001) Caries detection methods: can they aid decision making for invasive sealant treatment? Caries Res 35(2):83-89. https://doi.org/10.1159/00004 7437

49. Cortes DF, Ellwood RP, Ekstrand KR (2003) An in vitro comparison of a combined FOTI/visual examination of occlusal caries with other caries diagnostic methods and the effect of stain on their diagnostic performance. Caries Res 37(1):8-16. https://doi. org/10.1159/000068230

50. Angnes G, Angnes V, Grande RH, Battistella M, Loguercio AD, Reis A (2005) Occlusal caries diagnosis in permanent teeth: an in vitro study. Braz Oral Res 19(4):243-248. https://doi.org/10. 1590/s1806-83242005000400002

51. Erten H, Uctasli MB, Akarslan ZZ, Uzun O, Baspinar E (2005) The assessment of unaided visual examination, intraoral camera and operating microscope for the detection of occlusal caries lesions. Oper Dent 30(2):190-194

52. Mestriner SF, Vinha D, Mestriner Junior W (2005) Comparison of different methods for the occlusal dentine caries diagnosis. $\mathrm{J}$ Appl Oral Sci 13(1):28-34. https://doi.org/10.1590/s1678-77572 005000100007

53. Manton DJ, Messer LB (2007) The Effect of Pit and Fissure Sealants on the Detection of Occlusal Caries in Vitro. Eur Arch Paediatr Dent 8(1):43-48. https://doi.org/10.1007/bf03262569

54. Reis A, Mendes FM, Angnes V, Angnes G, Grande RH, Loguercio AD (2006) Performance of methods of occlusal caries detection in permanent teeth under clinical and laboratory conditions. J Dent 34(2):89-96. https://doi.org/10.1016/j.jdent.2005.04.002

55. Souza-Zaroni WC, Ciccone JC, Souza-Gabriel AE, Ramos RP, Corona SA, Palma-Dibb RG (2006) Validity and reproducibility of different combinations of methods for occlusal caries detection: an in vitro comparison. Caries Res 40(3):194-201. https://doi.org/ $10.1159 / 000092225$

56. Rodrigues Jde A, Hug I, Lussi A (2009) The influence of PVC wrapping on the performance of two laser fluorescence devices on occlusal surfaces in vitro. Photomed Laser Surg 27(3):435-439. https://doi.org/10.1089/pho.2008.2333

57. de Paula AB, Campos JA, Diniz MB, Hebling J, Rodrigues JA (2011) In situ and in vitro comparison of laser fluorescence with visual inspection in detecting occlusal caries lesions. Laser Med Sci 26(1):1-5. https://doi.org/10.1007/s10103-009-0731-y

58. Bucher K, Galler M, Seitz M, Hickel R, Kunzelmann KH, Kühnisch J (2015) Occlusal caries extension in relation to visual and radiographic diagnostic criteria: results from a microcomputed tomography study. Oper Dent 40(3):255-262. https://doi.org/10. 2341/13-128-L

59. Heinrich-Weltzien R, Weerheijm KL, Kühnisch J, Oehme T, Stösser L (2002) Clinical evaluation of visual, radiographic, and laser fluorescence methods for detection of occlusal caries. ASDC J Dent Child 69(2):127-132

60. Akarsu S, Koprulu H (2006) In vivo comparison of the efficacy of DIAGNOdent by visual inspection and radiographic diagnostic techniques in the diagnosis of occlusal caries. J Clin Dent 17(3):53-58

61. Huth KC, Neuhaus KW, Gygax M, Bucher K, Crispin A, Paschos E et al (2008) Clinical performance of a new laser fluorescence device for detection of occlusal caries lesions in permanent molars. J Dent 36(12):1033-1040. https://doi.org/10.1016/j.jdent. 2008.08.013

62. Bozdemir E, Karaarslan ES, Ozsevik AS, Ata Cebe M, Aktan AM (2013) In vivo performance of two devices for occlusal caries detection. Photomed Laser Surg 31(7):322-327. https://doi.org/ 10.1089/pho.2012.3458

63. Bahrololoomi Z, Ezoddini F, Halvani N (2015) Comparison of Radiography, Laser Fluorescence and Visual Examination for Diagnosing Incipient Occlusal Caries of Permanent First Molars. J Dent 12(5):324-332

64. Cotta F, de Castilho LS, Moreira AN, Paiva SM, Ferreira EF, Ferreira LC et al (2015) Lesion activity assessment (LAA) in conjunction with international caries detection and assessment system (ICDAS) for occlusal caries diagnosis in permanent teeth. Oper Dent 40(5):189-196. https://doi.org/10.2341/13-332-C

65. Castilho LS, Cotta FV, Bueno AC, Moreira AN, Ferreira EF, Magalhaes CS (2016) Validation of DIAGNOdent laser fluorescence and the International Caries Detection and Assessment System (ICDAS) in diagnosis of occlusal caries in permanent teeth: an in vivo study. Eur J Oral Sci 124(2):188-194. https://doi.org/ 10.1111/eos. 12257

66. Wenzel A, Hintze H, Mikkelsen L, Mouyen F (1991) Radiographic detection of occlusal caries in noncavitated teeth. A comparison of conventional film radiographs, digitized film radiographs, and RadioVisioGraphy. Oral Surg Oral Med Oral Pathol Oral Radiol Endod 72(5):621-626. https://doi.org/10.1016/0030-4220(91) 90504-6

67. Lussi A, Firestone A, Schoenberg V, Hotz P, Stich H (1995) In vivo diagnosis of fissure caries using a new electrical resistance monitor. Caries Res 29(2):81-87. https://doi.org/10.1159/ 000262046

68. Baseren NM, Gokalp S (2003) Validity of a laser fluorescence system (DIAGNOdent) for detection of occlusal caries in third molars: an in vitro study. J Oral Rehabil 30(12):1190-1194. https://doi.org/10.1111/j.1365-2842.2003.01164.x

69. Francescut P, Lussi A (2003) Correlation between fissure discoloration, Diagnodent measurements, and caries depth: an in vitro study. Ped Dent 25(6):559-564

70. Tranaeus S, Lindgren LE, Karlsson L, Angmar-Mansson B (2004) In vivo validity and reliability of IR fluorescence measurements for caries detection and quantification. Swed Dent J 28(4):173-182

71. Fung L, Smales R, Ngo H, Moun G (2004) Diagnostic comparison of three groups of examiners using visual and laser fluorescence methods to detect occlusal caries in vitro. Aust Dent J 49(2):6771. https://doi.org/10.1111/j.1834-7819.2004.tb00052.x

72. Lussi A, Hellwig E (2006) Performance of a new laser fluorescence device for the detection of occlusal caries in vitro. J Dent 34(7):467-471. https://doi.org/10.1016/j.jdent.2005.11.002

73. Rodrigues JA, Diniz MB, Josgrilberg EB, Cordeiro RC (2009) In vitro comparison of laser fluorescence performance with visual examination for detection of occlusal caries in permanent and primary molars. Laser Med Sci 24(4):501-506. https://doi.org/ 10.1007/s10103-008-0552-4

74. Rodrigues JA, Hug I, Neuhaus KW, Lussi A (2011) Light-emitting diode and laser fluorescence-based devices in detecting occlusal caries. J Biomed Opt 16(10):107003. https://doi.org/10.1117/1. 3631796

75. Aktan AM, Cebe MA, Ciftci ME, Sirin KE (2012) A novel LED-based device for occlusal caries detection. Lasers Med Sci 27(6):1157-1163. https://doi.org/10.1007/s10103-011-1020-0

76. Mortensen D, Dannemand K, Twetman S, Keller MK (2014) Detection of non-cavitated occlusal caries with impedance spectroscopy and laser fluorescence: an in vitro study. Open Dent J 8:28-32. https://doi.org/10.2174/1874210601408010028 
77. Bader JD, Shugars DA, Bonito AJ (2001) Systematic reviews of selected dental caries diagnostic and management methods. J Dent Educ 65(10):960-968

78. Bader JD, Shugars DA, Bonito AJ (2002) A systematic review of the performance of methods for identifying carious lesions. J Public Health Dent 62(4):201-213. https://doi.org/10.1111/j. 1752-7325.2002.tb03446.x

79. Bader JD, Shugars DA (2004) A systematic review of the performance of a laser fluorescence device for detecting caries. J Am Dent Assoc 135(10):1413-1426. https://doi.org/10.14219/jada. archive.2004.0051

80. Gimenez T, Braga MM, Raggio DP, Deery C, Ricketts DN, Mendes FM (2013) Fluorescence-based methods for detecting caries lesions: systematic review, meta-analysis and sources of heterogeneity. PLoS One 8(4):e60421. https://doi.org/10.1371/ journal.pone.0060421

81. Twetman S, Axelsson S, Dahlen G, Espelid I, Mejare I, Norlund A, Tranaeus S (2013) Adjunct methods for caries detection: a systematic review of literature. Acta Odontol Scand 71(3-4):388397. https://doi.org/10.3109/00016357.2012.690448

82. Pitts N (ed) (2009) Detection, assessment, diagnosis and monitoring of caries. Monogr Oral Sci 21:1-14. https://doi.org/10.1159/ isbn.978-3-8055-9185-0

83. Kühnisch J, Goddon I, Berger S, Senkel H, Bücher K, Oehme T, Heinrich-Weltzien R (2009) Development, methodology and potential of the new Universal Visual Scoring System (UniViSS) for caries detection and diagnosis. Int J Environ Res Public Health 6(9):2500-2509. https://doi.org/10.3390/ijerph6092500

84. Kühnisch J, Bücher K, Henschel V, Albrecht A, Garcia-Godoy F, Mansmann U, Heinrich-Weltzien R (2011) Diagnostic performance of the universal visual scoring system (UniViSS) on occlusal surfaces. Clin Oral Investig 15(2):215-223. https://doi. org/10.1007/s00784-010-0390-1

85. Drancourt N, Roger-Leroi V, Martignon S, Jablonski-Momeni A, Pitts N, Doméjean S (2019) Carious lesion activity assessment in clinical practice: a systematic review. Clin Oral Investig 23(4):1513-1524

86. Braga MM, Mendes FM, Ekstrand KR (2010) Detection activity assessment and diagnosis of dental caries lesions. Dent Clin North Am 54(3):479-493. https://doi.org/10.1016/j.cden.2010.03.006

87. Schwendicke F, Splieth C, Breschi L, Banerjee A, Fontana M, Paris S, Burrow MF, Crombie F, Page LF, Gatón-Hernández P, Giacaman R, Gugnani N, Hickel R, Jordan RA, Leal S, Lo E, Tassery H, Thomson WM, Manton DJ (2019) When to intervene in the caries process? An expert Delphi consensus statement. Clin Oral Investig 23(10):3691-3703. https://doi.org/10.1007/ s00784-019-03058-w

88. Kühnisch J (2020) Discussion on the paper: "When to intervene in the caries process? An expert Delphi consensus statement." Clin Oral Investig 24(5):1865-1867. https://doi.org/10.1007/ s00784-020-03271-y

89. Splieth CH, Banerjee A, Bottenberg P, Breschi L, Campus G, Ekstrand KR, Giacaman RA, Haak R, Hannig M, Hickel R, Juric H, Lussi A, Machiulskiene V, Manton DJ, Jablonski-Momeni A, Opdam NJM, Paris S, Santamaría RM, Schwendicke F, Tassery H, Ferreira Zandona A, Zero DT, Zimmer S, Doméjean S (2020) How to Intervene in the Caries Process in Children: A Joint ORCA and EFCD Expert Delphi Consensus Statement. Caries Res 54(4):297-305. https://doi.org/10.1159/000507692

90. Ekstrand KR, Kuzmina I, Bjørndal L, Thylstrup A (1995) Relationship between external and histologic features of progressive stages of caries in the occlusal fossa. Caries Res 29:243-250. https://doi.org/10.1159/000262076

91. Ekstrand KR, Martignon S, Ricketts DJ, Qvist V (2007) Detection and activity assessment of primary coronal caries lesions: a methodologic study. Oper Dent 32:225-235. https://doi.org/10. 2341/06-63

92. Neuhaus KW, Ellwood R, Lussi A, Pitts NB (2009) Traditional lesion detection aids. Detection, Assessment, Diagnosis and Monitoring of Caries. Monogr Oral Sci 21:42-51. https://doi.org/10. $1159 / 000224211$

93. Neuhaus KW, Longbottom C, Ellwood R, Lussi A (2009) Novel lesion detection aids. Detection, Assessment, Diagnosis and Monitoring of Caries. Monogr Oral Sci 21:52-62. https://doi.org/10. $1159 / 000224212$

94. Pinheiro IVDA, Medeiros MCDS, Ferreira MÂF, Lima KCD (2004) Use of laser fluorescence (DIAGNOdent) for in vivo diagnosis of occlusal caries: a systematic review. J Appl Oral Sci 12(3):177-181. https://doi.org/10.1590/S1678-775720040003000 03

Publisher's note Springer Nature remains neutral with regard to jurisdictional claims in published maps and institutional affiliations. 


\section{Authors and Affiliations}

\section{Svetlana Kapor ${ }^{1}$. Mila Janjic Rankovic ${ }^{2}$. Yegane Khazaei ${ }^{1,3}$ - Alexander Crispin ${ }^{3}$ - Ina Schüler ${ }^{4}$.}

Felix Krause $^{5} \cdot$ Adrian Lussi $^{6,7} \cdot$ Klaus Neuhaus $^{8,9} \cdot$ Florin Eggmann $^{8} \cdot$ Stavroula Michou $^{10} \cdot$ Kim Ekstrand $^{10}$. Marie-Charlotte Huysmans ${ }^{11}$. Jan Kühnisch ${ }^{1,12}$ (])

1 Department of Conservative Dentistry and Periodontology, University Hospital, Ludwig-Maximilian University, Munich, Germany

2 Department of Orthodontics and Dentofacial Orthopedics, University Hospital, Ludwig-Maximilian Universität München, Munich, Germany

3 Institute of Medical Biometry and Epidemiology, Ludwig-Maximilian University of Munich, Munich, Germany

4 Department of Orthodontics, Section of Preventive and Paediatric Dentistry, University Hospital, Jena, Germany

5 Clinic for Operative Dentistry, Periodontology and Preventive Dentistry, University Hospital RWTH Aachen, Aachen, Germany

6 Department of Operative Dentistry and Periodontology, Faculty of Dentistry, University Medical Centre, Freiburg, Germany
7 School of Dental Medicine, University of Bern, Bern, Switzerland

8 Clinic of Periodontology, Endodontology and Cariology, University Centre for Dental Medicine Basel, University of Basel, Basel, Switzerland

9 Department of Dermatology, Inselspital-Bern University Hospital, Bern, Switzerland

10 Department of Odontology, University Copenhagen, Copenhagen, Denmark

11 Department of Dentistry, Radboud University Medical Centre, Nijmegen, the Netherlands

12 Poliklinik Für Zahnerhaltung Und Parodontologie, Klinikum Der Universität München, LMU München, Goethestraße 70, 80336 München, Germany 